\title{
Multi-modelling for Decarbonisation in Urban Rail Systems
}

\author{
David Golightly ${ }^{1} \cdot$ Carl Gamble $^{2} \cdot$ Roberto Palacin $^{1}$ (D) Ken Pierce $^{2}$
}

Received: 21 June 2019/Revised: 9 September 2019/Accepted: 11 October 2019/Published online: 15 November 2019

(C) The Author(s) 2019

\begin{abstract}
This paper demonstrates a methodology for flexible, dynamic systems modelling relevant to urban rail decarbonisation. Decarbonisation of urban rail is a vital component of policy and strategy to minimize anthropogenic emissions. Decarbonisation is a systems problem, however, that needs to reflect the interaction between components and processes. Dynamic computer modelling of systems for decarbonisation involves interfacing multiple models together and running them in parallel in order to observe and predict systems-level effects. This is challenging due to the diverse nature of models, achieving parallel model integration and concerns around intellectual property (IP). One solution is the multi-modelling paradigm, which supports integrated, diverse, secure interfacing of models. This paper demonstrates the application of the multi-modelling approach, using the INTO-CPS tool chain. A multi-model was developed comprising key components required for urban rail decarbonisation problems. This multi-model was tested for power consumption in four different scenarios with an example drawn from the Tyne and Wear Metro in Newcastle-upon-Tyne in the United Kingdom. These scenarios compared combinations of decarbonisation intervention (baseline rolling stock versus lightweight, regenerative braking rolling stock and baseline driving style versus energy-efficient defensive
\end{abstract}

David Golightly

david.golightly@ncl.ac.uk

1 School of Engineering, Stephenson Building, Newcastle University, Newcastle upon Tyne NE1 7RU, UK

2 School of Computing, Urban Sciences Building, Newcastle University, 1 Science Square, Newcastle Helix, Newcastle upon Tyne NE4 5TG, UK

Communicated by Marin Marinov. driving style), generating different power consumption profiles for each. As such, this serves as a proof of the application of the multi-modelling approach and demonstrates a number of benefits for flexible and rapid systems modelling. This paper fills a knowledge gap by demonstrating a potentially valuable tool for future systems-level decarbonisation challenges in urban rail.

Keywords Dynamic modelling · Multi-modelling · Power optimisation · Decarbonisation · Railway

\section{Introduction}

This paper presents a methodology to assist in systemslevel modelling for decarbonisation of urban railways. In this paper, anthropogenic greenhouse gas (GHG) emissions will be referred to generally as carbon emissions, and the removal or reduction of these emissions as decarbonisation.

Decarbonisation is the critical societal challenge of our time, with the Paris Agreement setting out a framework to limit global temperature rise in this century to well below $2{ }^{\circ} \mathrm{C}$ above pre-industrial levels and to pursue efforts to limit the temperature increase to $1.5^{\circ} \mathrm{C}$ [1]. Transport is a significant aspect of this challenge, contributing around $20-25 \%$ of emissions [2], of which $25 \%$ is generated in urban environments [3]. Policy and strategy are in place [4] to drive rail's contribution through mechanisms such as local and regional commitments to rail [5], national-level policy to decarbonise rail [6] and international-level commitments to mode shift and rail electrification [7,8]. The aim is both to encourage rail travel as a mitigation of private vehicle emissions and to lower the emissions of rail travel itself, such as through efforts as part of Shift2Rail in the EU [9]. The decarbonisation of rail is particularly 
relevant to urban travel, given global trends towards increasing urbanisation [10] and the potential decarbonisation benefits specific to urban light rail $[3,11]$ such as a high degree of electrification. Electrified rail has $60 \%$ lower carbon emissions than diesel, rising to $90 \%$ with the estimated 2040 grid mix [4].

There is still scope however to improve the decarbonisation benefits of urban rail. Batteries [12, 13] are potentially advantageous as they can extend networks or close gaps in network where there is no electrification. Batteries can also be used with regimes such as discontinuous electrification [14]. Hydrogen technologies [15] have also been demonstrated to have substantial benefits to lowcarbon urban transport, without the potential capital costs of electrification, though the technology is still to be proven at scale. Power performance may be further improved through techniques such as driver advisory systems [16] or timetable optimisation for energy efficiency [17]. Also, decarbonisation relates to not only rolling stock but also power usage for infrastructure and assets [3] and is applicable across the whole lifecycle [18, 19].

Designing for urban rail decarbonisation is a systems problem in which it is not just the performance of individual components that defines carbon impact, but also the interaction of multiple components, often within an operational context [3, 20, 21]. Factors such as duty cycles [22] and local or temporary conditions may have an impact on performance; For example actual data on diesel-based urban rail emissions reveal significant fluctuations due to passenger loading or due to disruption and delay [11]. Similarly, real vehicle performance in electric-powered urban rail shows significant fluctuations due to factors such as variable wind resistance depending on weather, variable adhesion and fluctuations in power supply [23]. GonzálezGil et al. [24] demonstrates how holistic modelling of the system allows comparison and optimisation across seven different key performance indicators related to power performance on an urban network. One critical indicator for this paper is carbon emissions. In electrified rail networks, one major source of emissions is power consumption. In 2016, carbon emissions related to power generation in the UK ran at $275 \mathrm{~g}$ per $\mathrm{kWh}$ [25].

The challenge, therefore, is to predict system interactions in an accurate cost-effective manner to enable informed decision-making for design and operations. Subcomponents and processes of a rail system typically have associated simulation models, used for design or optimisation. These models may be dynamic: they express behaviour that changes over time and are typically discreteevent or continuous-time models [26]. Examples of tools used in rail discrete-event modelling include General Purpose Simulation System [27], Arena [28], Siuml8 [29] and MATLAB/Simlink [30]. Such models, however, are likely to have been built at different times in diverse formats for different purposes [31] and do not integrate readily to give the whole systems view required for decarbonisation. Models may be bespoke to particular suppliers, who also have concerns around the sharing of models, data and intellectual property (IP) [32]. These problems may be exacerbated when suppliers are new to the rail sector, such as the transfer of automotive lightweighting approaches to rail [33]. Typically, models from outside of rail conform to the standards and discipline norms of their domain and lack contextual expertise of rail [34]. The challenge, therefore, is to provide a flexible open environment where diverse types of model and data can be combined and run in parallel to identify whole-system dynamic properties.

One solution from outside of rail is multi-modelling [35]. Multi-modelling allows dynamic models to be interfaced and run together to understand emergent system behaviours relevant to decarbonisation. Multi-modelling has been used successfully in domains including automation [36], cyber-physical systems [37] and non-rail engine emission optimisation [38]. As yet, multi-modelling has not been applied to urban rail decarbonisation problems. The work presented in this paper evaluates the potential of this methodology to address urban rail decarbonisation. To do so, multi-modelling needs to be able to both capture valid aspects of an urban rail system and generate meaningful outputs. Furthermore, if multi-modelling is to offer benefits that are not seen through bespoke modelling of component models, it needs to be able to demonstrate flexibility and rapid integration of additional model components, and to be able to meet the needs of multiple scenarios.

The multi-modelling approach is tested through defining an urban rail multi-model populated by a number of source models covering train performance, power, movement authority and driver behaviour. These are then tested to analyse different driver styles and to compare a potential alternative rolling stock, as decarbonisation interventions. While the results of the modelling present different power outputs, the key point is not the quality of the modelling, which is relatively simple, but the flexibility and extendibility of the modelling approach using multimodelling.

The structure of the paper is as follows: Section 2 introduces the multi-modelling paradigm along with the INTO-CPS tool chain; Section 3 presents the urban rail multi-model, covering the methodological approach and the details of the source models; Section 4 presents the results of implementing the model to capture performance in scenarios with varying types of decarbonisation intervention; Section 5 discusses implications, and Sect. 6 offers future directions and conclusions. 


\section{Methodology: the Multi-modelling Paradigm}

While the use of modelling is widespread, each discipline has adopted their own techniques, tools and terminologies. For example discrete-event models may focus only on state changes [26], an approach shared with human performance models such as IMPRINT $^{\odot}$ [39]. Engineers might use continuous-time models to describe systems where the state changes continuously [26], using numerical methods to approximate the solutions or to divide complex systems into tractable parts using finite element method (FEM).

In order to analyse complex systems that cross multiple domains - computing, physical, human-it is necessary to develop tools that can capture these phenomena in a system model. One approach to building system models is to develop new languages that can represent a range of phenomena. At a minimum, this requires training engineers and practitioners to learn a brand-new tool. It is also likely that such a language would only partially capture phenomena in each domain. An alternative approach is to combine existing models into a single multi-model using a framework to manage their interaction. Such an approach allows for collaborative modelling by diverse teams using existing familiar tools and models, acting as a means of communication across disciplines and allowing for validation of designs much earlier in the design process [35]. This has particular potential for both systems and systemsof-systems modelling [40], as the approach can capture dynamic interactions between a number of source models. Multi-modelling thereby supports the integration of multiple models to be run in parallel, while still existing in their native form. Importantly, this means that numerous discrete-event and continuous-time models can be yoked together, and emergent systems effects may be observed.

The INTO-CPS technologies are a collection of tools based around multi-models [41]. These tools form a tool chain that can be used to analyse multi-models, for example, through co-simulation. The use of CPS in the acronym refers to cyber-physical systems. The INTO-CPS technologies are an open tool chain, maintaining a commitment to open source where possible and lowering the barrier to modelling and simulation, providing an alternative to commercial software from large vendors that could lock companies into using a single supplier. The INTOCPS Association is a not-for-profit group of organisations that maintain the technologies, based around a community of industrial users. A key element of the openness of INTO-CPS is the adoption of the Functional Mock-up Interface (FMI) standard for co-simulation [42]. The FMI standard originated in the automotive domain to connect models-packaged as Functional Mock-up Units (FMUs) - together to be simulated together.
Figure 1 shows part of the INTO-CPS tool chain relevant to this paper, focusing on co-simulation of FMUs. In a co-simulation, a collection of FMUs representing the system are simulated together under the control of a co-simulation engine, which manages the passage of time and transmission of data between the FMUs. INTO-CPS provides an FMI-compliant co-simulation engine called Maestro [43]. A collection of FMUs constitutes a multimodel. Co-simulation results are generated and managed within Maestro, while a front-end tool called the INTOCPS Application provides a graphical way to configure, run and inspect co-simulations. Critically, FMUs do not have to be completely exposed within INTO-CPS. Instead, only the relevant outputs of each model are exposed, while the model inside can be encrypted. This is vital in sectors where suppliers wish to protect the intellectual property of the constituents of their models and the products they represent.

Although over 30 other tools ${ }^{1}$ can produce FMUs, this study uses the discrete-event modelling language VDM-RT (Vienna Development Method-Real-Time dialect), supported by the Overture tool, and the continuous-time tool 20-sim. VDM-RT is an object-oriented modelling language which would be familiar to many programmers $[44,45]$. It can simulate discrete-event phenomena, and while it includes features for modelling embedded computing components, it can also be used to describe other logical processes. 20-sim [46] is a modelling tool that supports definition and simulation of continuous-time phenomena described through differential equations. These equations can be inputted directly and represented graphically using blocks and connections or through bond graphs, a domainindependent notation for describing physical phenomena.

The INTO-CPS tool chain includes a variety of other analysis techniques, including test-case generation and simulation with real signals from hardware. Successful applications of INTO-CPS include Foldager et al. [36], in which multi-modelling in the development and optimisation of a steering system for a driverless industrial-size lawn mower are used. Initial models of the kinematics, dynamics and steering control system are co-simulated to investigate the performance of the controller in a virtual setting. Neghina et al. [37] demonstrate the use of multimodelling for the design and validation of a robotic assembly line combining models including the robot arm, warehousing, part tracking, production and order-scheduling human-machine interface. Pedersen [38] applied the approach to combine models of both the cyber and physical aspects of an emission reduction system for a two-stroke engine.

\footnotetext{
${ }_{1}$ https://fmi-standard.org/tools/.
} 
Fig. 1 Co-simulation in the INTO-CPS tool chain [41]

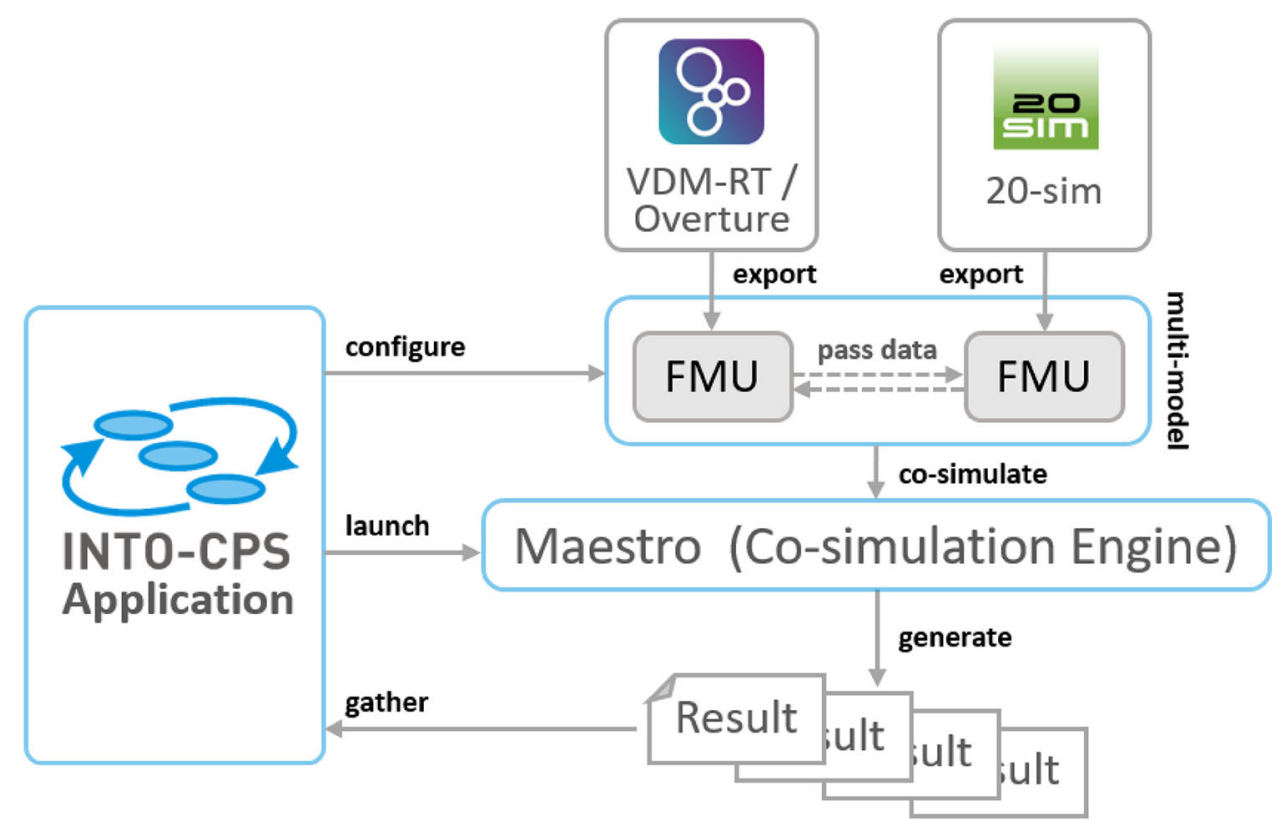

As such, multi-modelling through INTO-CPS should theoretically address the challenges of systems level decarbonisation modelling by:

- Supporting continuous time series models, such as battery life, power draw, rolling stock performance and external temperature

- Discrete event simulation, such as for driver behaviour, signalling and availability state of assets

- Co-simulation of systems decarbonisation by combining multiple system elements such as rolling stock performance using batteries at different external temperatures and duty cycles

- Rapid design space exploration, such as using multiple battery configurations and multiple charging configurations

- Retaining IP within the supply chain by allowing model builders/suppliers only to expose their model outputs through FMI

\section{Urban Rail Multi-model}

To test the utility of multi-modelling for urban decarbonisation problems, a proof-of-concept multi-model relevant to urban decarbonisation was constructed. This section outlines the construction of the multi-model in three phases-conceptual design of the multi-model, defining the source models and implementing the multi-model. This model has been implemented within INTO-CPS.

The context to be simulated was taken from the Tyne and Wear Metro in Newcastle-upon-Tyne in the United
Kingdom. The Tyne and Wear Metro provides a major transportation network into the cities of Newcastle upon Tyne and Sunderland and the surrounding urban and suburban areas. Opened in the 1980s, it uses a mixture of legacy infrastructure from the pre-existing urban rail network built in the 19th century and newer infrastructure built between the late 1970s through to the 1990s [47]. The network covers $77.5 \mathrm{~km}$ (48.2 miles) and 60 stations, 9 of which are underground. Rolling stock is powered by 1.5 $\mathrm{kV}$ DC overhead line throughout. Metro cars are 40 metric tonnes in weight. While most of the track is solely for Metro, there are points where services share the infrastructure with heavy rail, following the Karlsruhe model [48]. Metro has previously been served as a testbed for a number of modelling efforts and more general urban rail research $[23,49,50]$.

The specific location selected for modelling was between South Gosforth and Ilford Road Stations. This 800-m section lies in the core of the metro network, with short service headway during the peak (around 30 trains per hour). It is also one of the four track sections previously studied by Powell and Palacín [23], and thus provided data both for rolling stock and for validation.

\subsection{Conceptual Multi-model Architecture}

The phenomenon under scrutiny was carbon emissions, in terms of power usage [25], as affected by different configurations of rolling stock and driver behaviour for a sample area of track. To that end, the multi-model needed to represent infrastructure, including power supply; to describe realistic rolling stock performance, including 
power characteristics and regenerative braking; to describe driver behaviour, including more defensive, energy-efficient driving; and to support movement authority (i.e. a signalling system) to represent the communication to drivers when they have permission to proceed.

The initial step was to specify an overall multi-model architecture. This was designed with the intention of providing a generic simulation environment that could cover a variety of different modelling applications including power optimisation for rolling stock, including where rolling stock may include diesel [11, 48], power-optimised junction deconfliction and power modelling with different driving styles. The conceptual multi-model architecture was specified as follows:

1. Movement authority model-models the state of the signalling system for a specified area of the network and passes state to the driver;

2. Driver model - models the actions of the driver (apply power, apply brake) in response to movement authority and passes state to the train model;

3. Power model-models the availability of power to trains, thus passing power to trains. The design also supports receiving power from trains in a hypothetical situation where trains pass regenerative power back to the network;

4. Train model-models the behaviour of the train in response to the actions of the driver model. The train also draws power from the power model and can pass power back to the power model in a regenerative configuration.

Figure 2 shows the static structure of the multi-model. This shows the four FMUs representing the four rail phenomena and the data that are sent among them. The movement authority sends signals to the driver, based on the position of each train. The driver reads the speed and position of the train and sets the throttle and brake. The power model provides voltage to the train and measures energy used.

Multiple copies (instances) of FMUs can be created to represent different scenarios. In this case, there are two trains and two drivers controlled by a single movement authority and supplied by a single power system. This creates the dynamic (simulation-time) structure of the multi-model shown in Fig. 3. The diagram also shows the mapping between the rail phenomena and modelling paradigm of each FMU.

\subsection{Source Models}

Having defined a conceptual architecture for the multimodel, four source models were developed. In some cases, these came from pre-existing project work or, in other cases, were developed as needed for the decarbonisation multi-model.

\subsubsection{Train Model}

The train model represents rolling stock as is realised as a continuous-time model in 20-sim. This is presented in Fig. 4a, b.

Figure $4 \mathrm{a}$ shows the structure of the train FMU. This FMU contains three sub-models: parameters, passenger and train. The parameters block contains the global parameters for the FMU, including the train's mass and energy regeneration properties, which helps maintain consistency throughout the model. For this model, two train masses $[40,000 \mathrm{~kg}$ (baseline train), based on the weight of the current Metro rolling stock, and $35,000 \mathrm{~kg}$ for a hypothetical lightweight version] and two brake energy regeneration efficiencies [30\% (lightweight train) and $0 \%$ (baseline train-effectively no regeneration)] are used. The train block (detailed below) contains the dynamic model of the train, while the passenger block contains a simple spring-damper model used to indicate the effect of driver style on the passenger movement. The arrowed lines represent data exchanged between model elements. Arrows with names represent the interface of the FMU, arrows pointing out of the model are outputs of the FMU, while arrows pointing inwards are the inputs this FMU expects. Some parts of the interface represent data exchanges required for the model to function, e.g. sending speed to the driver and receiving control signals from the driver, while other parts of the interface are present to support analysis of the model, such as the energy consumed.

Figure $4 \mathrm{~b}$ presents the contents of the train block. Here we can see how the dynamics of the train are decomposed into further sub-models. There is a sub-model for the motor that uses the throttle and the current speed to compute both power draw and driving force utilising traction, power and speed data adapted for light rail from Powell et al. [50] and Mansfield [51]. The drag sub-model computes the aerodynamic drag given the train's speed. The simple brake sub-model computes the braking force applied to the train as a result of the brake signal from the driver; it also computes what proportion of the kinetic energy is recovered by regenerative braking. These forces are fed into the acceleration block, where the acceleration is computed, which is then integrated first to give speed and then again to give the train's position. Finally, the model contains an energy block which combines the power signals from the brakes and motor to give some overall train energy values. 


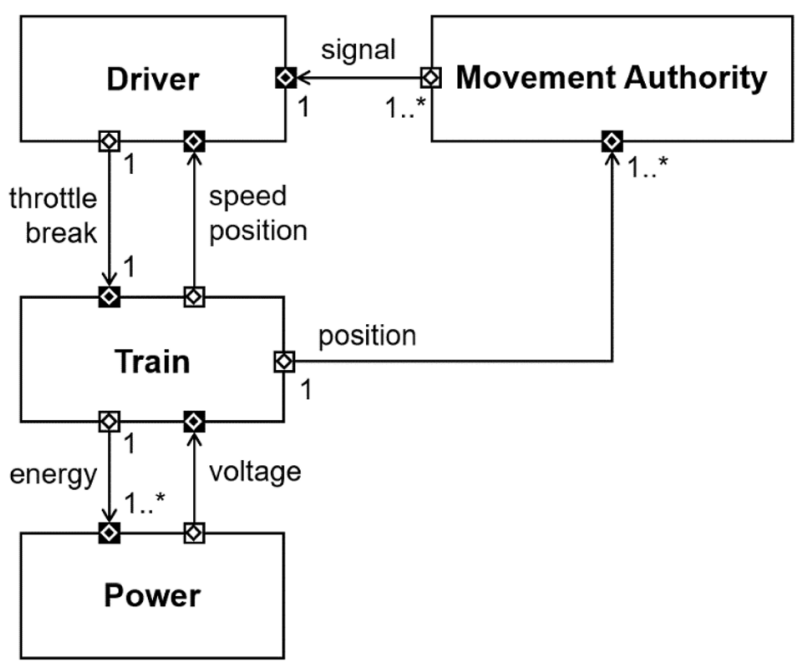

Fig. 2 Diagram showing the static FMU structure of the multi-model

\subsubsection{Movement Authority Model}

This model represents the state of the signalling system for any part of the network, and this provides the movement authority for any train. The model uses a discrete-event formalism VDM realised in the Overture tool. The model developed for this test application uses the signalling infrastructure between South Gosforth and Ilford Road Stations on the Tyne and Wear Metro system.

A class diagram for the core of the driver model is shown in Fig. 5. The model holds the topology of the signalling system, in this case, two two-aspect signals, each placed at the end of the respective station platforms. The model receives inputs giving the location of each train and changes the state of the signals as trains pass through. Signals are only set to green/proceed after a train has left the track section ahead, thus recreating a basic interlocking. In this scenario, this happens when the first train departs Ilford Road Station. In addition to updating the signal states, the model also communicates the state of the next signal that each driver (model) can see. By using this approach, new track segments can easily be added to reflect greater infrastructure complexity, or more complex (e.g. three-aspect) signalling is possible without requiring significant changes to the other constituent models of the multi-model.

\subsubsection{Driver Model}

The driver model is also realised as a discrete-event simulation in VDM. A class diagram for the core of the driver model is shown in Fig. 6. The driver model receives input from the movement authority in the form of the state of the next signal on the track. The model also receives input from the train model giving the position on track and the speed. The driver model decides whether to proceed or brake as required, based on the state of the next signal and the distance from it (e.g. slowing down ahead of a red/stop signal).

Following the Tyne and Wear Metro, braking was notched with three levels, with three levels of power [23]. The driver model includes two driver styles-a baseline who drives aggressively using the higher notches (e.g. full power and higher levels of braking), and a defensive driver who uses a lower power notch (typically used for a lowrail-adhesion situation) and lower brake notches. Defensive driving is known to be a more energy-efficient mode of driving [52] and is often supported through driver advisory systems $[16,45]$.
Fig. 3 Rail phenomena, modelling paradigms and dynamic FMU structure of the multi-model

\section{Rail phenomena Modelling paradigm}
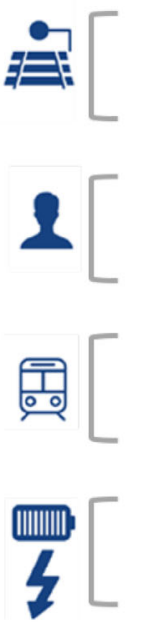
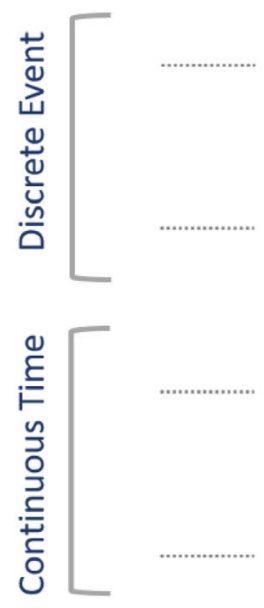

Multi-model structure

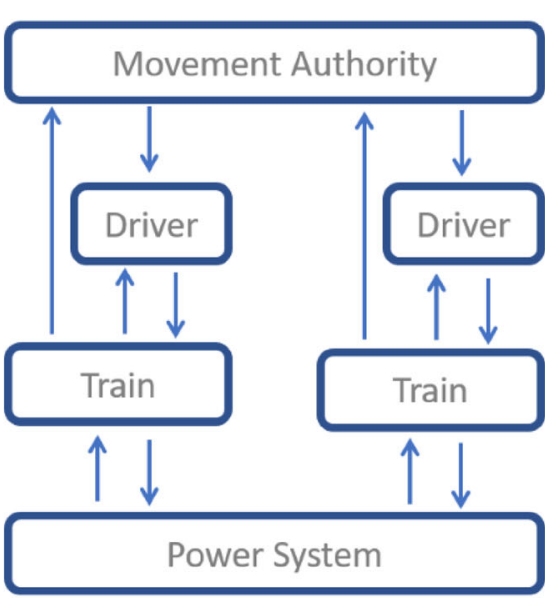


a
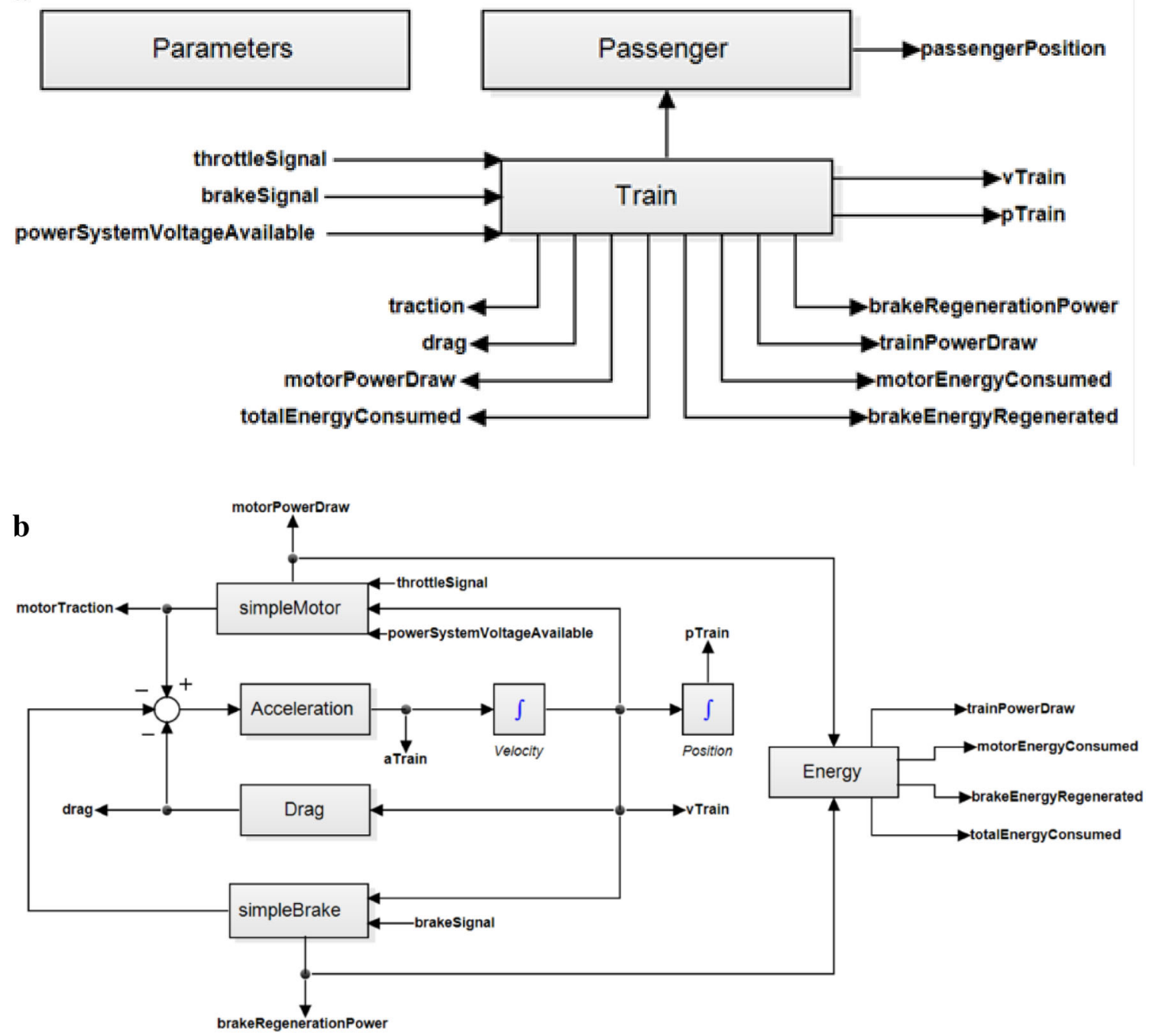

Fig. 4 a Structure of train FMU. b Structure of train sub-model

Fig. 5 Structure of the movement authority model

\begin{tabular}{|c|c|c|}
\hline MAuthority & & SensorReal \\
\hline \multirow{2}{*}{$\begin{array}{l}\text {-trains: map nat1 to TrainState } \\
\text {-signals: seq of nat } \\
\text {-signal_stages: map nat1 to bool }\end{array}$} & \multirow{3}{*}{$\begin{array}{c}\text { TrainState } \\
\text {-pos: SensorReal } \\
\text {-sig: ActuatorBool } \\
\text {-prev_pos: real }\end{array}$} & -port: RealPort \\
\hline & & +getValue(): real \\
\hline \multirow{2}{*}{$\begin{array}{l}\text { +MAuthority(...): MAuthority } \\
+ \text { +Step(): void } \\
\text {-next_signal(real): int }\end{array}$} & & ActuatorBool \\
\hline & & -port: BoolPort \\
\hline & & $\begin{array}{l}\text { +setValue(bool): void } \\
\text { +getValue(): real }\end{array}$ \\
\hline
\end{tabular}

\subsubsection{Power Supply Model}

As with the train model, the power supply model was developed as a continuous-time model in 20-sim. The power FMU has outputs providing line voltage to the train FMUs and receives inputs yielding how much power the trains uses. From these inputs, the FMU computes the total power drawn by the trains. In this study, the power model is idealised (there are no losses on the lines or voltage drops, for example) and the trains can always draw as much power as they need. This serves as a useful test model that could easily be extended to be realistic and include energy storage, or more realistically could be replaced by a high- 
Fig. 6 Structure of the driver model

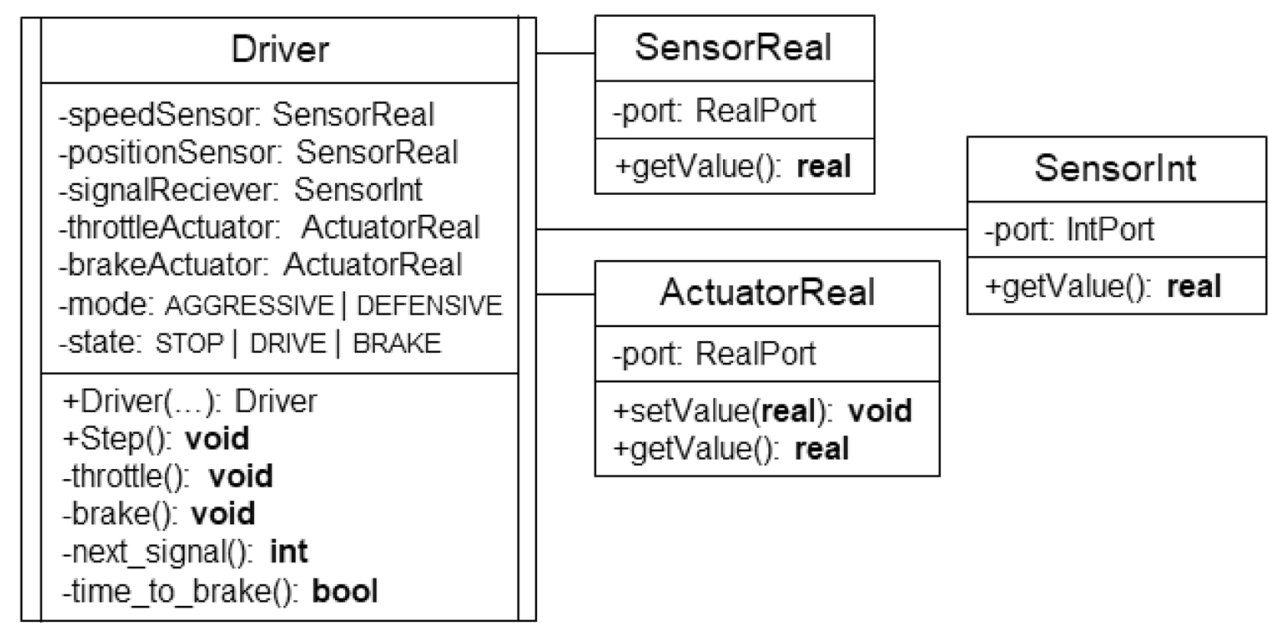

fidelity power model from a dedicated power simulation tool.

\subsection{Multi-model Implementation}

Once the first versions of the source models were finished and the interfaces agreed, FMUs were exported from each of the tools. The INTO-CPS application was then used to compose them into a multi-model, which requires selecting the FMUs and defining the number of instances each of them require: in this case, two trains, two drivers and one each for the power and movement authority FMUs. Creating the multi-model also requires connecting the inputs and outputs between instances (e.g. train position to driver and movement authority). Finally, initial parameters, such as initial train positions, and settings, such as cosimulation length and step size, are set. As models were updated to add fidelity or fix problems, these were swapped in to update the multi-model; this could be done simultaneously by team members working on the individual models.

Four different multi-models were created describing the four different scenarios:

1. Baseline driver with standard rolling stock

2. Baseline driver with power-optimised (lightweight + regenerative braking) rolling stock

3. Defensive driver with standard rolling stock

4. Defensive driver with power-optimised (lightweight + regenerative braking) rolling stock

In all four scenarios, the initial parameters for position, signals and the co-simulation settings were the same. The driver model included the two styles of driving that could be changed with a parameter (keeping the same FMU), while the two rolling stock options were created as separate FMUs with the same interface, which could represent two different suppliers providing models of their rolling stock performance.

\section{Results}

Figure 7 presents outputs for scenario 2, a power-optimised train with baseline (aggressive) driving. The two trains start at $0.4 \mathrm{~km}$ and $1.2 \mathrm{~km}$, standing still at the signals of South Gosforth Station and Ilford Road Station, respectively. Train 1 leaves the station (Ilford Road) and accelerates to line speed at $20 \mathrm{~s}$ and continues at that speed throughout the remainder of the simulation. Train 2 leaves the station (South Gosforth) at $8 \mathrm{~s}$, after receiving a green signal, and accelerates towards Ilford Road Station before decelerating into the station at $60 \mathrm{~s}$. These behaviours correspond to the outputs of the driver for each train, applying power and brakes based on the movement authority. In terms of energy consumption, as train 2 applies braking on approach to Ilford Road Station, power consumption reduces through the effects of regenerative braking. The position, speed and energy plots represent outputs from the continuous-time source models, while the throttle and brake plots represent outputs from a discreteevent source model.

Overall journey time for a baseline (non-lightweight, non-regenerative) train with baseline (non-defensive) driving (scenario 1) for train 2 between South Gosforth and Ilford Road Stations was $56 \mathrm{~s}$. This gives similar model performance to service times presented by Powell and Palacín [23] of $60 \mathrm{~s}$. Where both trains are lightweight/ regenerative, but with a baseline driving style (scenario 2), travel time for train 2 between the two stations is $52 \mathrm{~s}$, reflecting the higher acceleration possible due to a lower mass.

Where both trains are baseline but use defensive driving (scenario 3 ), the time taken by train 2 between the two 
Fig. 7 Clockwise from top left: train positions, driver outputs, energy consumptions and train speeds for a single scenario (baseline driver and lightweight rolling stock)
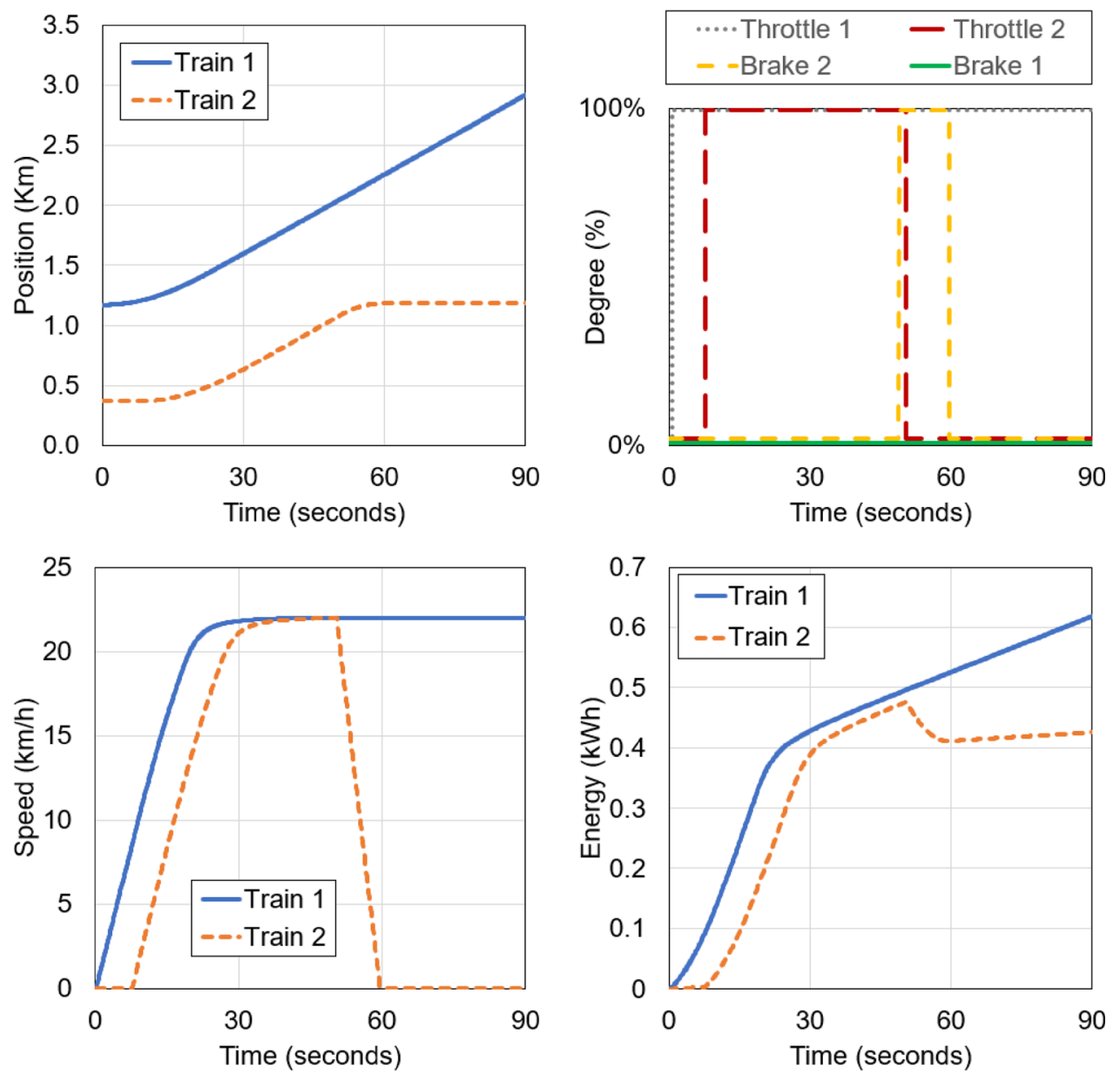

stations is $82 \mathrm{~s}$; however, it also departs later from South Gosforth Station (10 s into the simulation rather than $8 \mathrm{~s}$ ) due to the defensive style of train 1 in leaving Ilford Road Station and therefore clearing the track section. Lightweight with defensive driving (scenario 4) for train 2 takes $65 \mathrm{~s}$ between the two stations, though it is still slower in its departure from South Gosforth Station in comparison with the baseline driving style because of the later departure of the train ahead.

Figure 8 shows the cumulative power consumption (combined train 1 and train 2) for each scenario. Power consumption was then equated with carbon emissions by multiplying joules to carbon at a rate of $275 \mathrm{~g}$ per $\mathrm{kWh}$ [25], presented on the right-hand axis. The lightweight and regenerative rolling (scenario 2) stock offers similar decarbonisation benefits to defensive driving (scenario 3 ) in comparison with scenario 1 , but both combined (scenario 4) offer the best power performance.

\section{Discussion}

The model described above has generated demonstrable differences in power performance for a series of small test urban rail decarbonisation scenarios. They offer general face validity, particularly in terms of travel time and expected variation under different decarbonisation efforts. However, the more relevant outcomes are with regards to the advantages of using multi-modelling.

First, it has been possible to develop models in the appropriate format for the relevant modelling approach. In the multi-modelling approach above, the train and power models are realised as continuous-time models (as shown in Fig. 7). The driver and movement authority models, however, have been implemented with a discrete-event formalism. These, respectively, are the natural forms of implementation for each model type. Despite these different approaches, they have been run concurrently to generate systems-level modelling outputs.

Second, each model is an instance, which can be replicated $n$ times. In the multi-model architecture described above, two trains and two driver models have been used. These instances can be adapted to model different 
Fig. 8 Energy (kWh) and carbon $(\mathrm{g})$ used against time (s) for the four simulations

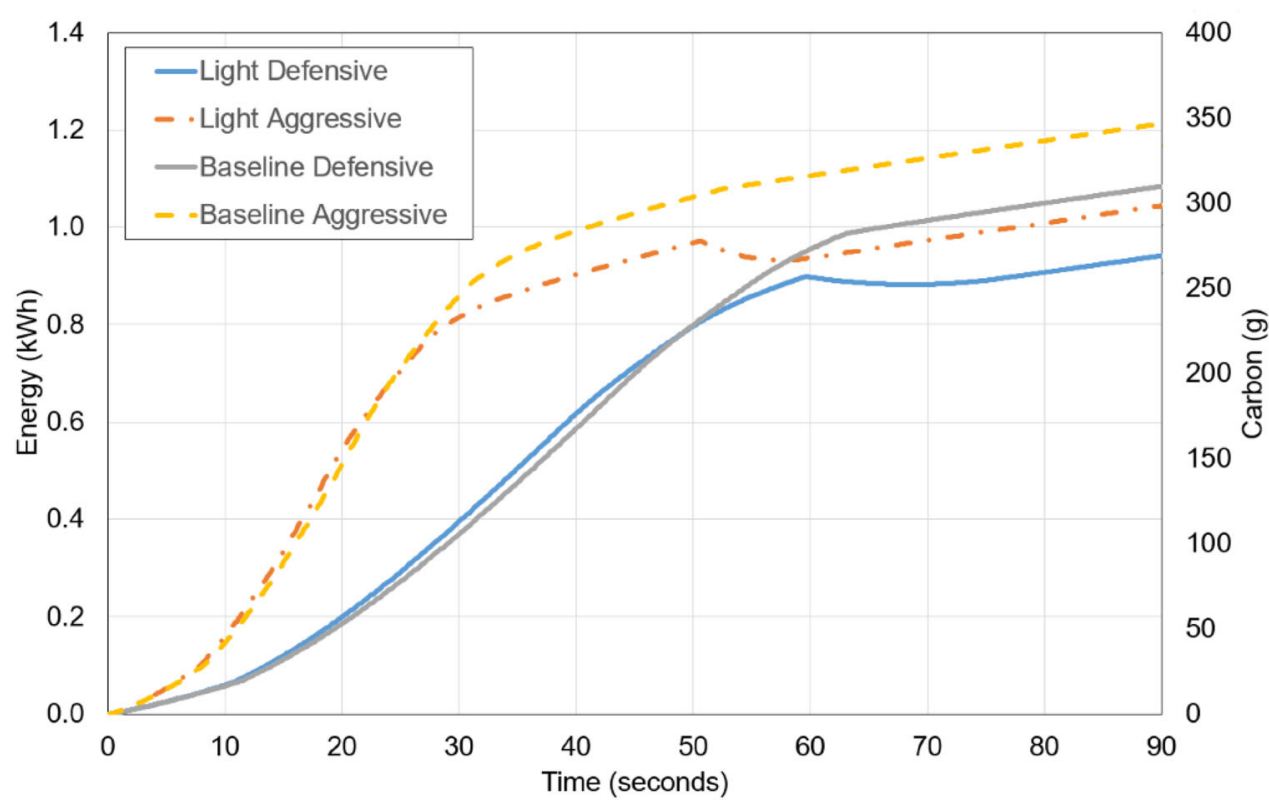

configurations and/or performance. In the example, different driver models have been combined and different train models generated. In the example scenarios described above, different rolling stock, and aggressive and defensive drivers have been combined. However, further combinations could be rapidly reconfigured, for example, to test an intermediate condition where both baseline and lightweight rolling stock are combined in traffic, or different drivers have different styles concurrently on the network.

As instances can be run concurrently, it is possible to observe system-level effects [3, 11, 20, 23]. These system effects can be seen in terms of decarbonisation. Combining lightweighting, regenerative power and defensive driving gives better performance in comparison with all other conditions. These results are also consistent with the notion that decarbonisation choices may have wider system effects [3], for example, in terms of timetable performance, as seen in the longer travel times with defensive driving. Finally, these system effects can be seen in the fact that there are multiple instances. In comparison with Powell and Palacín [23], this ability to run more than one train has shown an effect in terms of defensive driving for train 1 slowing the departure of train 2 from South Gosforth Station.

Third, the modelling approach, using FMU (Fig. 3a), means only the relevant and necessary aspects of the model need to be exposed, theoretically maintaining IP within a supply chain [27, 33]. In the current scenario, the power, movement authority and driver model could be held by an operator, and the train model supplied by a rolling stock provider. In such a scenario, the rolling stock supplier only has to expose rolling stock performance through the FMU, without having to expose how this is derived. This is relevant to Metro, which is currently in a procurement process for new rolling stock.

Finally, the multi-model described offers flexibility as there are multiple ways in which both the models described and the multi-model as a whole could be extended. Table 1 lists potential extensions based on data or phenomena found in prior research, or other forms of metro system. While the example presented in this paper has used a combination of bespoke source models and models taken from the authors' previous work, this basic multi-model can now be extended to accommodate other models, as long as the model either is FMI compliant or could be made compliant to generate an FMU. A specific future step is to develop this multi-model to examine more realistic power consumption performance, particularly for regenerative braking [13] and a more accurate, actual driver behaviour model based on Metro performance data [54] and humanin-the-loop simulation. Importantly, the ability of the multi-model to support multiple instances means it will be possible to model not just the power implications of driver performance on one driver but also how different drivers with different performance cause system interactions in the timetable and, subsequently, with power performance.

There are, nonetheless, challenges with the use of multimodelling. First, the process is expedited if tools and models are already FMI compliant. An audit of the rail sector is currently in progress, and the early evidence is that compliance and general awareness of FMI are limited to a few major organisations. This reflects a wider challenge of standardisation in information and communication technology (ICT) across the rail sector [32]. The solution is that the rail sector, or at least the suppliers of modelling software within the rail sector, undertake work to make the 
Table 1 Example extensions to urban rail multi-model relevant to decarbonisation

\begin{tabular}{|c|c|}
\hline Model & Example extensions \\
\hline Movement authority & More complex network; three-aspect signalling; traffic optimisation [17] \\
\hline Driver model & Driver advisory systems $[16,54]$; driving style [23] \\
\hline Train model & $\begin{array}{l}\text { Passenger loading [11]; resistance due to weather/wind [23]; adhesion [23]; mix of diesel/heavy rail with urban electric } \\
\text { rail (further use of Karlsuhe model [48]) }\end{array}$ \\
\hline $\begin{array}{l}\text { Regenerative braking } \\
\text { model }\end{array}$ & Different regenerative braking capacities [11]; battery models [13] under different temperatures [12] \\
\hline Power supply model & Non-infinite power supply/power fluctuation [23]; discontinuous electrification [14]; lineside storage [13] \\
\hline
\end{tabular}

outputs of modelling software compliant. Alternatively, in cases where this is not possible, bespoke FMU models could be made. While this may seem like extra effort, because of the open and compliant nature of multi-modelling, those models would be amenable to re-use.

The second major challenge is validity. In theory, when suppliers provide their source models, these are already valid. However, there is a concern that bespoke models would have to be validated. The train models show good performance consistency with Powell and Palacín [23], but there is further work to validate other aspects such as the power model. Also, when models are combined, there is the risk of combinatorial errors due to interactions of minor errors in each of the source models.

A final challenge is co-simulation performance. While the combination of tools through multi-modelling provides flexibility, there is a performance overhead that comes from synchronising data between multiple models compared to a single bespoke tool. This can be mitigated by scaling up compute resource (for example use of flexible cloud computing) and through careful experiment design (minimising the number of full co-simulations required to produce results).

\section{Conclusions}

This paper has described an approach, multi-modelling, that can assist in system modelling to support decarbonisation efforts. This has been achieved through a flexible multi-model design that can be applied to multiple problems within a real urban rail system. The benefits to urban rail are cheaper and more rapid iterations of system models, with the ability to explore different configurations of components or operational practices. In this paper we have mostly focused on rolling stock design and operation, but multi-modelling has the potential to apply to any aspect of the rail system where dynamic modelling could explore and support the reduction of carbon emissions. Real driver behaviour has already been mentioned above. Other future directions include applications as diverse as agent-based modelling for optimised design for buildings usage [55], for subway climatology [56] or optimising construction processes and logistics to minimise both transportation carbon emissions and material waste [57].

Acknowledgements This work was funded by the Rail Safety and Standards Board (RSSB) as the Digital Environment for Collaborative Intelligent De-carbonisation (DECIDe) project (COF-IPS-06).

Open Access This article is distributed under the terms of the Creative Commons Attribution 4.0 International License (http://crea tivecommons.org/licenses/by/4.0/), which permits unrestricted use, distribution, and reproduction in any medium, provided you give appropriate credit to the original author(s) and the source, provide a link to the Creative Commons license, and indicate if changes were made.

\section{References}

1. UNFCCC (2015) Adoption of the Paris Agreement. Report No. FCCC/CP/2015/L.9/Rev.1, http://unfccc.int/resource/docs/2015/ cop21/eng/109r01.pdf. Accessed 20 Sept 2019

2. IEA and UIC (2012) Railway handbook 2012 - energy consumption and $\mathrm{CO}_{2}$ emissions, International Energy Agency. http://www.uic.org/IMG/pdf/iea-uic_energy_consumption_and_ co2_emission_of_world_railway_sector.pdf. Accessed $20 \mathrm{Sept}$ 2019

3. González-Gil A, Palacin R, Batty P, Powell JP (2014) A systems approach to reduce urban rail energy consumption. Energy Convers Manag 80:509-524

4. RSSB (2019). T1145 Options for traction energy decarbonisation in rail: Final Report July 2019. https://www.rssb.co.uk/Pages/ research-catalogue/T1145.aspx. Accessed 20 Sept 2019

5. Transport for London (2018) The Mayor's Transport Strategy, March 2018. https://www.london.gov.uk/what-we-do/transport/ ourvision-transport/mayors-transport-strategy-2018?intcmp= 46686. Accessed 20 Sept 2019

6. Department for Transport (2018) Transcript of Minister of State at the Department for Transport, 12 February 2018. https://www. gov.uk/government/speeches/lets-raise-our-ambitions-for-a-clea ner-greenerrailway. Accessed 20 Sept 2019

7. International Energy Agency (2019) The future of rail. Opportunities for energy and the environment. IEA Publications. https:// webstore.iea.org/the-future-of-rail

8. European Rail Research Advisory Council (2017) Rail 2050 Vision: Rail-The Backbone of Europe's mobility. http://www. 
errac.org/wp-content/uploads/2018/01/122017_ERRAC-RAIL2050.pdfRSSBstrategy. Accessed 20 Sept 2019

9. Shift2Rail (2015) Shift2Rail Joint Undertaking: Multi-Annual Action Plan, 15 November 2015. https://shift2rail.org/wp-con tent/uploads/2013/07/S2R-JU-GB_Decision-N-15-2015-MAAP. pdf. Accessed 20 Sept 2019

10. UN (United Nations) (2018) 2018 revision of world urbanisation prospects. UN Population Division, New York

11. Graver BM, Frey HC (2016) Highway vehicle emissions avoided by diesel passenger rail service based on real-world data. Urban Rail Transit 2(3-4):153-171

12. Yang N, Zhang X, Shang B, Li G (2016) Unbalanced discharging and aging due to temperature differences among the cells in a lithium-ion battery pack with parallel combination. J Power Sources 306:733-741

13. Hayashiya H (2017) Recent trend of regenerative energy utilization in traction power supply system in Japan. Urban Rail Transit 3(4): 183-191

14. Hoffrichter A, Silmon J, Schmid F, Hillmansen S, Roberts C (2013) Feasibility of discontinuous electrification on the Great Western Main Line determined by train simulation. Proc Inst Mech Eng Part F J Rail Rapid Transit 227(3):296-306

15. Marin GD, Naterer GF, Gabriel K (2010) Rail transportation by hydrogen vs. electrification-case study for Ontario Canada, I: propulsion and storage. International Journal of Hydrogen Energy 35(12):6084-6096

16. Rahn K, Bode C, Albrecht T (2013) Energy-efficient driving in the context of a communications-based train control system (CBTC). In: 2013 IEEE international conference on intelligent rail transportation proceedings, pp 19-24. IEEE

17. Botte M, D'Acierno L (2018) Dispatching and rescheduling tasks and their interactions with travel demand and the energy domain: models and algorithms. Urban Rail Transit 4(4):163-197

18. Milford R, Allwood J (2010) Assessing the $\mathrm{CO}_{2}$ impact of current and future rail track in the UK. Transp Res Part D 15:61-72

19. Ortega A, Blainey S, Preston J (2018) Assessing whole-life carbon footprint of under sleeper pad installation for ballasted track. J Transp Eng Part A Syst 144(12):04018073

20. Roskilly AP, Palacin R, Yan J (2015) Novel technologies and strategies for clean transport systems. Appl Energy 157:563-566

21. Marinov $M$ (2014) An intensive programme in railway and logistics. Res Transp Econ 41

22. Rail Industry Association (2019) RIA cost challenge electrification report. https://www.riagb.org.uk/RIA/Newsroom/Stories/ Electrification_Cost_Challenge_Report.aspx. Accessed 20 Sept 2019

23. Powell JP, Palacín R (2015) A comparison of modelled and reallife driving profiles for the simulation of railway vehicle operation. Transp Plan Technol 38(1):78-93

24. González-Gil A, Palacin R, Batty P (2015) Optimal energy management of urban rail systems: key performance indicators. Energy Convers Manag 90:282-291

25. Staffell I (2017) Measuring the progress and impacts of decarbonising British electricity. Energy Policy 102:463-475

26. Robinson S (2004) Simulation: the practice of model development and use. Wiley, New York

27. Marinov MV, Viegas JM (2011) Tactical management of rail freight transportation services: evaluation of yard performance. Transp Plan Technol 34(4):363-387

28. Kamrani M, Abadi SMHE, Golroudbary SR (2014) Traffic simulation of two adjacent unsignalized T-junctions during rush hours using Arena software. Simul Model Pract Theory 49:167-179

29. Wales J, Marinov M (2015) Analysis of delays and delay mitigation on a metropolitan rail network using event based simulation. Simul Model Pract Theory 52:52-77
30. Wang Q, Lu J, Wang Q, Duan J (2017) Transient overvoltage study of auto-passing neutral section in high-speed railway. In: 2017 IEEE transportation electrification conference and expo, Asia-Pacific (ITEC Asia-Pacific), pp 1-5. IEEE

31. Chen L, James P, Kirkwood D, Nguyen HN, Nicholson GL, Roggenbach M (2016) Towards integrated simulation and formal verification of rail yard designs-an experience report based on the UK East Coast Main Line. In: 2016 IEEE international conference on intelligent rail transportation (ICIRT), pp 347-355. IEEE

32. Golightly D, Easton JM, Roberts C, Sharples S (2013) Applications, value and barriers of common data frameworks in the rail industry of Great Britain. Proc Inst Mech Eng Part F J Rail Rapid Transit 227(6):693-703

33. Winnett $\mathrm{J}$, Iraklis A, Keating EM, McGordon A, Ridler T, Hughes DJ (2017). Automotive to rail: can technologies cross the gap? In: Proceedings of the Stephenson Conference

34. Palacin R, Golightly D, Ramdas V, Dadashi N (2016) Evaluating the impact of rail research: principles to maximise innovation uptake. Proc Inst Mech Eng Part F J Rail Rapid Transit 230(7):1673-1686

35. Fitzgerald J, Larsen PG, Verhoef M (eds) (2014) Collaborative design for embedded systems: co-modelling and co-simulation. Springer, Berlin

36. Foldager F, Larsen PG, Green O (2017) Development of a driverless lawn mower using co-simulation. In: Workshop on formal co-simulation of cyber-physical systems (CoSim-CPS)

37. Neghina M, Zamfirescu C-B, Pierce K (xxxx) Early-stage analysis of cyber-physical production systems through collaborative modelling. In: Software and systems modeling (SoSyM), Springer, Berlin (in press)

38. Pedersen N, Lausdahl K, Sanchez EV, Larsen PG, Madsen J (2017) Distributed co-simulation of embedded control software with exhaust gas recirculation water handling system using INTO-CPS. In: International conference on simulation and modeling methodologies, technologies and applications

39. Laughery K, Lebiere C, Archer S (2006) Modeling human performance in complex systems in handbook of human factors and ergonomics, 3rd edn. Wiley, New York, pp 965-996

40. Axelsson J (2015) Systems-of-systems for border-crossing innovation in the digitized society-A strategic research and innovation agenda for Sweden, SICS Technical Report T2015:07

41. Larsen PG, Fitzgerald J, Woodcock J, Gamble C, Payne R, Pierce $\mathrm{K}$ (2018) Features of integrated model-based co-modelling and co-simulation technology. In: Cerone A, Roveri M (eds) Software engineering and formal methods (SEFM). Springer, Cham

42. Blochwitz T, Otter M, Arnold M, Bausch C, Elmqvist H, Junghanns A, Mauß J, Monteiro M, Neidhold T, Neumerkel D, Olsson H (2011) The Functional Mockup Interface for tool independent exchange of simulation models. In: Proceedings of the 8th international modelica conference; March 20th-22nd; Technical Univeristy; Dresden; Germany, No. 063, pp 105-114. Linköping University Electronic Press

43. Thule C, Lausdahl K, Gomes C, Meisl G, Larsen PG (2019) Maestro: The INTO-CPS co-simulation framework. Simul Modell Pract Theory 92:45-61

44. Larsen PG, Lausdahl K, Battle N, Fitzgerald J, Wolff S, Sahara S, Verhoef M, Tran-Jørgensen PWV, Oda T (2013) VDM-10 language manual. Technical Report TR-001, The Overture Initiative. http://www.overturetool.org/. Accessed 20 Sept 2019

45. Verhoef M, Larsen PG (2006) Enhancing VDM ++ for modeling distributed embedded real-time systems. Technical Report, Radboud University Nijmegen

46. Broenink JF (1999) 20-sim software for hierarchical bond-graph/ block-diagram models. Simul Pract Theory 7(5-6):481-492

47. Young A (1999) Suburban railways of Tyneside. Bairstow, UK 
48. Priemus H, Konings R (2001) Light rail in urban regions: what Dutch policymakers could learn from experiences in France, Germany and Japan. J Transp Geogr 9(3):187-198

49. Powell JP, Palacín R (2015) Passenger stability within moving railway vehicles: limits on maximum longitudinal acceleration. Urban Rail Transit 1(2):95-103

50. Powell JP, Fraszczyk A, Cheong CN, Yeung HK (2016) Potential benefits and obstacles of implementing driverless train operation on the Tyne and Wear Metro: a simulation exercise. Urban Rail Transit 2(3-4):114-127

51. Mansfield M (2019) A systematic approach to model-based engineering of cyber-physical system of systems. Doctoral dissertation, Newcastle University

52. Luijt RS, van den Berge MP, Willeboordse HY, Hoogenraad JH (2017) 5 years of Dutch eco-driving: managing behavioural change. Transp Res Part A Policy Pract 98:46-63
53. Large DR, Golightly D, Taylor EL (2014) The effect of driver advisory systems on train driver workload and performance. In: Contemporary ergonomics and human factors 2014: proceedings of the international conference on ergonomics and human factors 2014, Southampton, UK, p 335

54. Rjabovs A, Palacin R (2017) The influence of system designrelated factors on the safety performance of metro drivers. Proc Inst Mech Eng Part F J Rail Rapid Transit 231(3):317-328

55. Chapman J, Siebers PO, Robinson D (2018) On the multi-agent stochastic simulation of occupants in buildings. J Build Perform Simul 11(5):604-621

56. Qian Z (2017) Integrated evaluation of air flow and gas dispersion for underground station safety strategies based on subway climatology, Doctoral dissertation, Newcastle University

57. Ryan B, Qu R, Schock A, Parry T (2011) Integrating human factors and operational research in a multidisciplinary investigation of road maintenance. Ergonomics 54(5):436-452 